\title{
Prognostic Value of Time Dependent Voltage Abatement During Remote Magnetic Navigation Guided Ablation in Idiopathic Right Ventricular Outflow Tract Arrhythmias
}

\author{
Raluca Sirbu Prisecaru*, Leila Riahi, Yves De Greef, Dirk Stockman and Bruno Schwagten \\ ZNA Middelheim Cardiovascular Center, Antwerpen, Belgium
}

Submission: April 24, 2019; Published: May 17, 2019

*Corresponding author: Raluca Sirbu Prisecaru, Department of Cardiology Polisano Hospital Sibiu, Izvorului Street, Sibiu, Romania

\begin{abstract}
Prognostic value of time dependent voltage abatement during remote magnetic navigation guided ablation in idiopathic right ventricular outflow tract arrhythmias

Purpose: We set out to evaluate if time related voltage abatement (dV/dt) of ventricular electrograms (EGM) during catheter ablation of idiopathic right ventricular outflow tract (RVOT) arrhythmias using the Stereotaxis Niobe II system is an efficient marker of long-term procedural success.

Methods: Twenty-six consecutive patients with acute success of RVOT ablation for premature ventricular contractions (PVCs) and/ or ventricular tachycardia (VT) suggestive of RVOT origin were included. Late success was defined as freedom of ventricular ectopies originating from the RVOT after 3 months of follow up without antiarrhythmic drugs (AAD).

Results: After 3 months follow-up 20 of 26 patients (77\%) remained free of symptoms and arrhythmias (group 1) and recurrences occurred in 6 patients (23\%) (group 2). 'Warming up' during RF applications occurred respectively in $85 \%$ and $83,33 \%$ of patients ( $\mathrm{p}=0,46)$, after a mean period (dt 2) of 4,72 $\pm 9,42$ vs 10,75 $\pm 11,34 \mathrm{sec}(\mathrm{p}=0,045)$. The time intervals from the onset of RF delivery (t0) to significant voltage abatement $(>90 \%)$ or reversal of EGM polarity ( $\mathrm{t} 1$ ) between the two groups were: $9,11 \pm 5,11$ vs $32,16 \pm 10,33(\mathrm{p}=0,00006)$. $\mathrm{dV} / \mathrm{dt} 1$ was $95,44 \pm 87,6 \mathrm{vs}$ $23,5 \pm 16,97 \mu \mathrm{V} / \mathrm{s}(\mathrm{P}=0,024)$.
\end{abstract}

Conclusion: Time related voltage abatement of ventricular EGM together with time interval from onset of RF ablation to significant voltage abatement $(>90 \%)$ or reversal of EGM polarity and time interval from RF delivery to onset 'warming up' are possible predictors of long term success after RF ablation of idiopathic RVOT arrhythmias.

Keywords: Voltage abatement of ventricular EGM; RF ablation; Idiopathic RVOT arrhythmias

Abbreviations: EGM: Electrograms; RVOT: Right Ventricular Outflow Tract; PVCs: Premature Ventricular Contractions; VT: Ventricular Tachycardia; AAD: Antiarrhythmic Drugs; ARVD: Arrhythmogenic Right Ventricular Dysplasia; LV: Left Ventricular; RF: Radiofrequency

\section{Introduction}

Arrhythmias originating from the right ventricular outflow tract (RVOT) tend to present as isolated premature ventricular complexes (PVCs), runs of non-sustained VT or sustained VT [1]. Unless it is the initial sign of an arrhythmogenic right ventricular dysplasia (ARVD), the prognosis is generally good, with an excellent long-term survival. For symptomatic patients in whom $\beta$-adrenergic blockers, calcium channel blockers [2,3] or antiarrhythmic drugs (AAD) class IC and III are ineffective [4] or not desired and for patients in whom left ventricular (LV) dysfunction occurs [5-7] radiofrequency (RF) ablation is a safe and effective treatment option [8].

The acute success rate for ablation of RVOT ectopies in nonstructural heart disease ranges from 65 to $97 \%$ [9-11]. When RF ablation is not successful [12-14], this can be due to intramural or epicardial origin of ectopies, occurrence of multiple morphologies of ectopic beats in the same patient or matching between the 
clinical VT and pace-map being less than 11 out of 12 leads. Despite high acute success rates, there is a recurrence rate of $5-23 \%$ during a follow up to 2 years [15-17].

Endocardial activation time at the successful ablation site is the only predictor of long-term tachycardia recurrence reported in literature to our knowledge [18]. Remote magnetic navigation (RMN) mapping and ablation of RVOT ectopies guided by the Stereotaxis Niobe II system (Stereotaxis, Inc., St Louis, MO, USA) appears to be safe, fast and effective [19]. The aim of our study was to evaluate if time related voltage abatement $(\mathrm{dV} / \mathrm{dt})$ of ventricular electrograms (EGM) during catheter ablation of idiopathic RVOT arrhythmias guided by RMN is an efficient marker of long-term procedural success.

\section{Methods}

\section{Study population}

Between July 2012 and January 2015, 26 patients with acute success of RVOT ablation for premature ventricular contractions (PVCs) and/or VT suggestive of RVOT origin were included in this study. All patients provided written informed consent. Patients were symptomatic and have been refractory to at least one AAD. Transthoracic echocardiography was performed in all patients for assessing right and left ventricle dimensions and left ventricle ejection fraction.

\section{Mapping and ablation}

PVCs were documented on the Lab System PRO ${ }^{\mathrm{TM}}$ EP recording system (Bard Electrophysiology Division, Lowell, MA, USA). All procedures were performed under local anesthesia. After obtaining vascular access, one 8F sheath was positioned in the right femoral vein. Navigation to the RVOT was performed utilizing a 3,5 mm tip irrigated magnetic catheter (Navi Star RMT Thermo Cool, Bio sense Webster, Diamond Bar, CA, USA). Detailed mapping was performed with the CARTO 3D mapping system (Bio sense Webster, Diamond Bar, CA, USA). The catheter movement within the RVOT was guided remotely by the Stereotaxis Niobe II system.

An activation map was made for each patient in order to determine the earliest local bipolar activation point $(\geq 30 \mathrm{~ms}$ from the onset of the QRS) (Figure 1). If PVCs were not occurring frequently, Isoproterenol (15 to $30 \mathrm{mcg} / \mathrm{min}$ ) was administered, and if this did not successfully increase the amount of ectopic beats, ablation was finally performed using pace mapping only. Pacing with output just above the threshold targeted the most optimal pace map ( $\geq 11 / 12$ leads). After the focus of PVCs was identified, RF delivery was applied with a maximal power of 40 $\mathrm{W}$, maximal temperature of $48^{\circ} \mathrm{C}$ during 60 to 120 seconds and catheter irrigation flow set at $17 \mathrm{ml} / \mathrm{min}$. Catheter stability was analyzed semi quantitatively. If the ablation catheter displaced during application, RF delivery was interrupted. Procedural endpoint was the elimination of spontaneous clinical PVCs at baseline and after Isoproterenol $(15 \mathrm{mcg} / \mathrm{min})$ infusion postablation. A waiting period of $30 \mathrm{~min}$ was applied for all procedures.

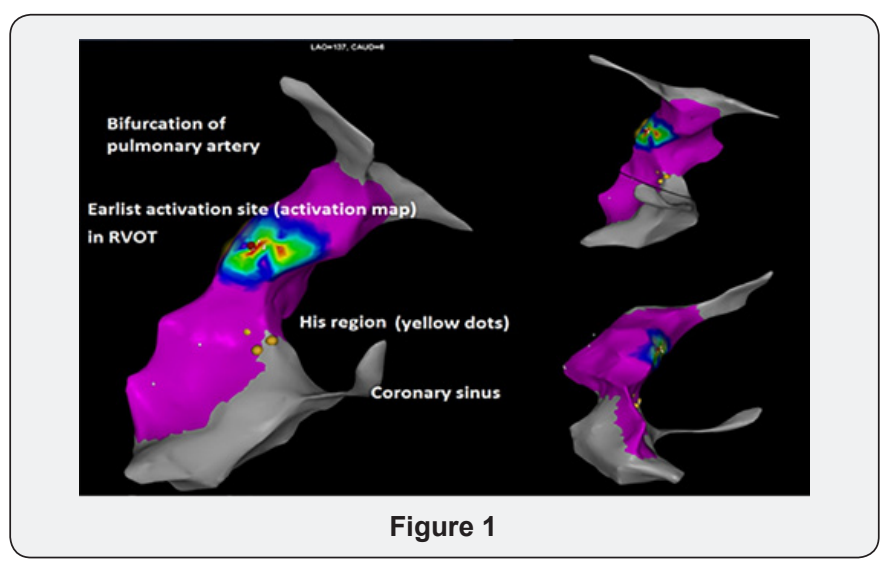

\section{Parameters}

The time interval from the onset of RF delivery (t0) to significant voltage abatement ( $>90 \%$ ) or reversal of EGM polarity (t1), as well as ventricular EGM amplitude during baseline (V0) and the new EGM amplitude during RF delivery at the moment of significant voltage abatement or reversal of EGM polarity (V1), were registered for each site of RF application. Thereafter, the difference between EGM amplitude (dV=V0-V1) and the time interval between $\mathrm{t} 0$ - $\mathrm{t} 1(\mathrm{dt} 1)$ were calculated for each site of $\mathrm{RF}$ application. If warming up during $\mathrm{RF}$ occurred, time interval from onset of RF ablation to warming up of the arrhythmia (dt2) was also registered (Figure 2). Procedural time, radiofrequency application time and fluoroscopy time were collected at the end of the procedure.

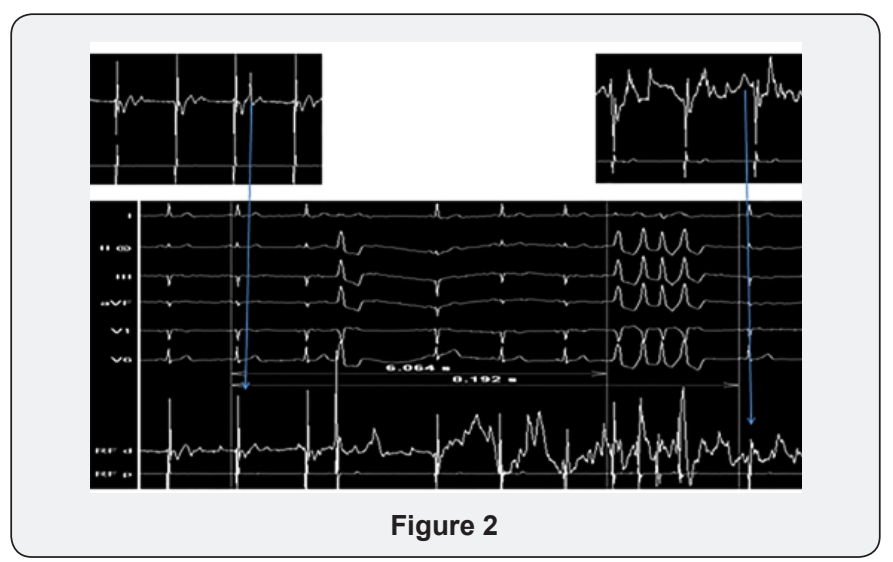

Post-procedural management

AAD were discontinued after RF ablation. All patients underwent follow-up at 1 and 3 months. Follow-up examinations consisted of symptom-based evaluation, 12-lead ECG and 24-h Holter-monitoring. Late success was defined as freedom of ectopies identical to the preprocedural ectopies, without AAD at 3 months of follow-up.

\section{Endpoints}

The primary endpoints were defined as recurrence rate of clinical PVCs at 3 months after ablation, the relationship between $\mathrm{dV} / \mathrm{dt} 1, \mathrm{dt} 1, \mathrm{dt} 2$ and recurrence versus absence of PVCs and/or VT. 


\section{Statistical analysis}

Categorical variables are expressed as frequencies and percentages. Continuous data are presented as mean value plus standard deviation. Continuous variables were analysed with a paired t-test. A P-value $<0.05$ was considered statistically significant.

\section{Results}

\section{Procedural data}

Data are summarized in Table 1. RVOT was identified as the origin of the VES/VT in all 26 patients. Successful RVOT ablation sites were identified using a combined activation and pacing map in 19 patients $(73 \%)$ and only a pacing map in 7 patients $(27 \%)$. Acute success was obtained in all patients. After a waiting time of 30 minutes, no patient presented PVC recurrence with the same morphology as the clinical arrhythmia. Mean total procedural time was $98,60 \pm 30,93 \mathrm{~min}$, mean total fluoroscopy time $2,97 \pm$ 1,67 minutes and mean radiofrequency ablation time was 353,20 $\pm 193,38$ seconds. During and after the procedure, no pericardial tamponade, cardiac perforation or other major adverse event occurred.

Tabel 1: Clinical characteristics and procedural parameters in patients undegoing RF ablation.

\begin{tabular}{|c|c|}
\hline Female (percentage) & $57,69 \%$ \\
\hline Mean age (years) & $41 \pm 15,27$ \\
\hline Activation + pacing map (percentage) & $73 \%$ \\
\hline Location focus & $50 \%$ (13 patients) \\
Free wall : & $50 \%$ (13 patients) \\
Septal: & $69 \%$ (18 patients) \\
\hline Type of arrhythmia: & $23 \%(6$ patients) \\
PVCs only: & $8 \%(2$ patients) \\
NSVT : & 22 patients (84,61\%) \\
\hline Sustained VT: & $98,60 \pm 30,93$ minutes \\
\hline Occurrence of „warming up" during RF & $2,97 \pm 1,67$ minutes \\
\hline Mean total procedural time & $353,20 \pm 193,38$ seconds \\
\hline Mean fluoroscopy time & \\
\hline Mean RF application time &
\end{tabular}

PVC, premature ventricular contraction; NSVT, non sustained ventricular tachycardia; VT, ventricular tachycardia

\section{Outcome after RVOT ablation}

At 3 months of follow-up, 20 of 26 patients (76,92\%) remained free of symptoms and arrhythmias (group 1). During a mean period of follow up thereafter of $13,55 \pm 10,15$ months, these patients presented no recurrence. During the 3 months of follow up, recurrences occurred with evidence of VES or/and VT in 6 patients (group 2). Three out of 6 patients underwent a second RF ablation. After 3 months of follow up after the second procedure, all patients were free of arrhythmias and symptoms. In one of these 3 patients, success was obtained after both right and left sided ablation. There was no significant difference with regard to clinical characteristics (gender, age) and several electrophysiological findings (type of map, the location of ectopic focus and the type of arrhythmia) between patients with long term successful ablation and those with recurrence of arrhythmia (Table 2).

Tabel 2: Clinical characteristics and electrophysiological findings between patients with successful and failed ablation.

\begin{tabular}{|c|c|c|c|}
\hline & Group 1 & Group 2 & P value \\
\hline Female & $65 \%$ & $33 \%$ & $\mathrm{P}=\mathrm{NS}(0,16)$ \\
\hline Activation + pacing map & $83,33 \%$ & $70 \%$ & $\mathrm{P}=\mathrm{NS}(0,26)$ \\
\hline Location focus : & $55 \%$ & $83,33 \%$ & \\
Free wall & $45 \%$ & $16,67 \%$ & $\mathrm{P}=\mathrm{NS}(0,53)$ \\
Septal wall & & $50 \%$ & \\
\hline Type of arrhythmia: & $75 \%$ & $33 \%$ & $\mathrm{P}=\mathrm{NS}(0,11)$ \\
PVCs only & $20 \%$ & $16 \%$ & \\
NSVT & $5 \%$ & & \\
Sustained VT & &
\end{tabular}

PVC, premature ventricular contraction; NSVT, non sustained ventricular tachycardia

'Warming up' during RF applications occurred respectively in $85 \%$ and $83,33 \%$ of patients ( $\mathrm{p}=0,46)$, after a mean time (dt 2 ) of $4,72 \pm 9,42$ vs $10,75 \pm 11,34 \mathrm{sec}(\mathrm{p}=0,045)$. The time intervals from the onset of RF delivery ( $\mathrm{t} 0$ ) to significant voltage abatement $(>90 \%)$ or reversal of EGM polarity ( $\mathrm{t} 1$ ) between the two groups were: $9,11 \pm 5,11$ vs $32,16 \pm 10,33(\mathrm{p}=0,00006)$ and $d V / d t 1$ was $95,44 \pm 87,6$ vs $23,5 \pm 16,97 \mu \mathrm{V} / \mathrm{s}(\mathrm{P}=0,024)$ (Table 3$)$. Total $\mathrm{RF}$ application times for the two groups were $351,5 \pm 206,31$ versus $370 \pm 120,96$ seconds $(\mathrm{p}=0,4)$.

Tabel 3: Procedural parameters in patients with long term success (group 1) versus recurrence (group 2).

\begin{tabular}{|c|c|c|c|}
\hline & $\begin{array}{c}\text { Group 1(20 } \\
\text { patients) }\end{array}$ & $\begin{array}{c}\text { Group 2(6 } \\
\text { patients) }\end{array}$ & P value \\
\hline Mean dt1 (sec) & $9,11 \pm 5,11$ & $32,16 \pm 10,33$ & $\mathrm{P}=0,00006^{*}$ \\
\hline Mean dt2 (sec) & $4,72 \pm 9,42$ & $10,75 \pm 11,34$ & $\mathrm{P}=0,045^{*}$ \\
\hline $\begin{array}{c}\text { Mean dV/dt1 } \\
(\mu \mathrm{V} / \mathrm{sec})\end{array}$ & $95,44 \pm 87,6$ & $23,5 \pm 16,97$ & $\mathrm{P}=0,024^{*}$ \\
\hline
\end{tabular}

${ }^{*} \mathrm{P}<0,05 \mathrm{dt} 1$, the time interval from the onset of RF delivery to significant voltage abatement (>90\%) or reversal of EGM polarity; dt2, time interval from onset of RF ablation to warming up of the arrhythmia; $d V / d t 1$, the difference between EGM amplitude at the onset of RF application to significant voltage abatement $(>90 \%)$ or reversal of EGM polarity corelated to the time interval $\mathrm{dt} 1$.

\section{Discussion}

The rate of recurrence of $23,08 \%$ after a follow period of $13,55 \pm 10,15$ months is similar with those reported in literature. The $76,92 \%$ success rate from the series suggests that long term successful ablation of RVOT arrhythmia can be achieved in patients who present during RF ablation with a short time interval between onset of RF delivery ( $\mathrm{t} 0$ ) to significant voltage abatement $(>90 \%)$ or reversal of EGM polarity (t1) and a higher value of voltage abatement correlated to time interval between $\mathrm{t} 0$ and $\mathrm{t} 1$. 
'Warming up' is not a predictor of procedural success in the long run, even though shorter time intervals between the onset of RF delivery and onset of warming up (dt2) trend towards predicting long term success.

Successful transmural lesion formation during RF ablation is the result of an ideal combination of contact force, catheter stability, tissue temperature and wall thickness. The mechanisms underlying long term recurrence of ventricular arrhythmias originating from RVOT are unknown but are likely due to inadequate lesion formation during the initial procedure. This may be due to the inability of achieving transmural lesions caused by poor catheter stability or insufficient wall contact creating acute tissue edema causing only temporary suppression of arrhythmias. In standard electrophysiological settings, changes in EGM morphology are the only way of determining successful transmural lesion formation. The speed at which this reduction in EGM amplitude occurs, now seems to represent the most ideal combination of wall contact, catheter precision and efficient transmural lesion formation.

Several studies already proved the superiority of RMN guided ablation of VT compared with manual navigation in terms of acute success rate and procedure and fluoroscopy times [20]. First, this finding could be explained by the higher navigation capability, even in difficult positions, due to the absence of pre-defined catheter curves. Secondly, the positioning of the tip, the catheter stability and contact are improved due to the constant magnetic force directing the tip during application, allowing appropriate lesion formation. Thirdly, RMN requires lower forces to maintain stable tissue contact than conventional manual ablation while creating equivalent lesions, making it also very suitable to be used in thin walled regions such as the outflow tracts.

It has been previously reported that mural swelling develops acutely in response to focal $\mathrm{RF}$ application. The swelling is most marked at the site of RF delivery, but also tends to spread, presumably through extension of interstitial edema through the adjacent tissue, preventing optimal catheter tissue contact and RF energy delivery. This tissue swelling persists throughout the time of the ablation procedure and appears to resolve only within weeks to months. So, while acute edema may result in temporary suppression of arrhythmias, long term scarring may not have been achieved, leading to recurrence. Therefore, it is paramount to achieve adequate lesion formation as soon as possible during the ablation procedure without causing too much 'collateral damage' by edema formation.

\section{Study Limitations}

This study has some limitations: the number of patients included is relatively small and this is a nonrandomized, retrospective study. However, since the $d t 1, d t 2, d V / d t 1$, were identified in our study as long-term outcome predictors post RVOT ablation, we believe that further studies and investigations are appropriate to confirm and establish a cut off value of dt1, dt2 and $\mathrm{dV} / \mathrm{dt} 1$ as possible predictors of long-term success.
There was no significant difference of time of RF application between our 2 groups, and thus the hypothesis, that some patients are more prone to development of edema, exists.

\section{Conclusion}

Time related voltage abatement of ventricular EGM together with time interval from onset of RF ablation to significant voltage abatement ( $>90 \%$ ) or reversal of EGM polarity and time interval from onset of RF ablation to 'warming up' are possible predictors of long-term success after RF ablation of idiopathic RVOT arrhythmias. Presence of 'warming up' however is not significantly correlated to procedural success in the long run.

\section{References}

1. Bernard Belhassen (2005) Radiofrequency Ablation of Benign Right Ventricular Outflow Tract Extrasystoles. Journal of the American College of Cardiology 45 (8): 1266-1268.

2. Buxton AE, Waxman HL, Marchlinski FE, Simson MB, Cassidy D, et al. (1983) Right ventricular tachycardia: clinical and electrophysiologic characteristics. Circulation 68(5): 917-927.

3. Gill JS, Mehta D, Ward DE, Camm AJ (1992) Efficacy of flecainide, sotalol, and verapamil in the treatment of right ventricular tachycardia in patients without overt cardiac abnormality. Br Heart J 68(4): 392397.

4. Hoffmayer KS, Gerstenfeld EP (2013) Diagnosis and management of idiopathic ventricular tachycardia. Crr Probl Cardiol 38 (4): 131-158.

5. Mountantonakis SE, Frankel DS, Gerstenfeld EP, Dixit S, Lin D, et al. (2011) Reversal of outflow tract ventricular premature depolarizationinduced cardiomyopathy with ablation: effect of residual arrhythmia burden and preexisting cardiomyopathy on outcome. Heart Rhythm 8(10): 1608-1614.

6. Ban JE, Park HC, Park JS, Nagamoto Y, Choi JI, et al. (2013) Electrocardiographic and electrophysiological characteristics of premature ventricular complexes associated with left ventricular dysfunction in patients without structural heart disease. Europace 15(5): 735-741.

7. Bogun F, Crawford T, Reich S, Koelling TM, Armstrong W (2007) Radiofrequency ablation of frequent, idiopathic premature ventricular complexes: comparison with a control group without intervention. Heart Rhythm 4(7): 863-867.

8. Zhu DW, Maloney JD, Simmons TW (1995) Radiofrequency catheter ablation for management of symptomatic ventricular ectopic activity. J Am Coll Cardiol 26(4): 843-849.

9. Joshi S, Wilber DJ (2005) Ablation of idiopathic right ventricular outflow tract tachycardia: current perspectives. J Cardiovasc Electrophysiol16(Suppl1): S52-S58.

10. Calvo N, Jongbloed M, Zeppenfeld K (2013) Radiofrequency catheter ablation of idiopathic right ventricular outflow tract arrhythmias. Indian Pacing Electrophysiol J 13(1): 14-33.

11. Stevenson WG, Soejima K (2007) Catheter Ablation for Ventricular Tachycardia. Circulation 115(21): 2750-2760.

12. Yokokawa M, Good E, Crawford T, Chugh A, Pelosi F, et al. (2013) Reasons for failed ablation for idiopathic right ventricular outflow tract-like ventricular arrhythmias. Heart Rhythm 10(8): 1101-1118.

13. Azegami K, Wilber DJ, Arruda M, Lin AC, Denman RA (2005) Spatial resolution of pacemapping and activation mapping in patients with idiopathic right ventricular outflow tract tachycardia. J Cardiovasc Electrophysiol 16(8): 823-829. 
14. Rodriguez LM, Smeets JL, Timmermans C, Wellens HJ (1997) Predictors for successful ablation of right and leftsided idiopathic ventricular tachycardia. Am J Cardiol J 79(3): 309-314.

15. O Donnell D, Cox D, Bourke J, Mitchell L, Furniss S (2003) Clinical and electrophysiological differences between patients with arrhythmogenic right ventricular dysplasia and right ventricular outflow tract tachycardia. Eur Heart J 24(9): 801-810.

16. Vestal M, Wen MS, Yeh SJ, Wang CC, Lin FC, et al. (2003) Electrocardiographic predictors of failure and recurrence in patients with idiopathic right ventricular outflow tract tachycardia and ectopy who underwent radiofrequency catheter ablation. J Electrocardio 36(4): 327-332.

17. Krittayaphong R, Sriratanasathavorn C, Dumavibhat C, Pumprueg $S$, Boonyapisit W, et al, (2006) Electrocardiographic predictors of long- term outcomes after radiofrequency ablation in patients with right ventricular outflow tract tachycardia. Europace 8(8): 601-606.

18. Wen MS, Taniguchi Y, Yeh SJ, Wang CC, Lin FC, et al. (1998) Determinants of tachycardia recurrences after radiofrequency ablation of idiopathic ventricular tachycardia. Am J Cardiol 81(4): 500-503.

19. Konstantinidou M, Koektuerk B, Wissner E, Schmidt B, Zerm T, et al (2011) Catheter ablation of right ventricular outflow tract tachycardia: a simplified remote-controlled approach. Europace13(5): 696-700.

20. Bauerenfeind T, Akca F, Schwagten B, De Groot N, Van Belle Y, et al. (2011) The magnetic navigation system allows safety and high efficacy for ablation of arrhythmias. Europace 13(7): 1015-1021

\begin{tabular}{|l|}
\multicolumn{1}{|c|}{ Your next submission with Juniper Publishers } \\
will reach you the below assets \\
- Quality Editorial service \\
- Swift Peer Review \\
- Reprints availability \\
- E-prints Service \\
- Manuscript Podcast for convenient understanding \\
- Global attainment for your research \\
- Manuscript accessibility in different formats \\
( Pdf, E-pub, Full Text, Audio) \\
- Unceasing customer service \\
Track the below URL for one-step submission \\
https://juniperpublishers.com/online-submission.php \\
\hline
\end{tabular}

